\title{
Analysis of diesel engine isolation system with piston slap
}

\author{
Song Yuchao ${ }^{1}$, Liao Jianbin², Yu Hongliang ${ }^{3}$ \\ ${ }_{1,2,3}$ Marine Engineering College, Dalian Maritime University, Dalian, China \\ ${ }^{2,3}$ Marine Engineering College, Jimei University, Xiamen, China \\ ${ }^{1}$ Corresponding author

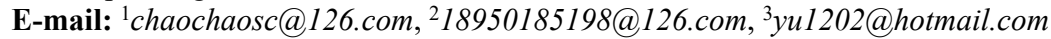

Received 11 January 2019; accepted 21 January 2019

DOI https://doi.org/10.21595/vp.2019.20515

Check for updates

Copyright $(2019$ Song Yuchao, et al. This is an open access article distributed under the Creative Commons Attribution License, which permits unrestricted use, distribution, and reproduction in any medium, provided the original work is properly cited.

\begin{abstract}
An isolation system of diesel engine with cylinder gap was modeled to deeply study the effect of piston shock on the whole vibration system. With the diesel engine rotates at rated speed, the center of engine body mass moves in plane with an obvious ellipse, and the magnitude is enlarged high to 3.5 times of the origin. All the bottom three directional springs have the corresponding response with the fundamental frequency signal, and a characteristic frequency band, as the piston slap is considered.
\end{abstract}

Keywords: diesel engine, isolation, piston slap, multi-body dynamics.

\section{Introduction}

Diesel engine produces a certain amount of noise in operation. The main noise is mechanical noise generated by combustion process. Piston is the main moving part of diesel engine which produces mechanical noise. It bears gas force and inertia force when it works. In diesel engine, because of the gap between cylinder liner and piston, piston moves reciprocating along the axis of cylinder liner, it has weak translation and rotation inside the cylinder liner at the same time, which is the second-order motion of piston. When the speed is high or the pressure of the cylinder is high, it can produce considerable scratching force and knocking force, which results in scratching or knocking on the cylinder liner. These two forces are a very important source of excitation for generating the mechanical noise of the diesel engine [1]. Therefore, it is very important to study and analyze the motion of piston for designing low-noise diesel engine.

For a long time, the research on vibration characteristics of diesel engine has been done by many works, including the piston slap and its noise identification [2, 3]. Nowadays, with the developing of computer-aided engineering, the numerical computation can be easily performed, such as the whole engine isolation vibration system model and its analysis [4]. In abroad, not only the piston slap, but also its effect on the cavitation of wet cylinder liner are the main research contents [5-10].

In this paper, for deeply study the piston slap and later analysis of its effect on the cavitation in diesel engine [11], a diesel engine isolation system with cylinder gap is modeled in ADAMS. The specific research and main content are to build the movement of the diesel engine parts and establish the contact constraint of piston and cylinder liner, and then analyze the effect of piston impact on the system response.

\section{Formula analysis of piston shock}

For a piston moving in the cylinder, the side trust $F_{s t}$ is always composed of three parts, including the component force of gas force $F_{g}$, reciprocating inertia force $F_{O G}$ and gravity force $F_{G}$ of reciprocating parts, which is expressed as:

$F_{s t}=\left(F_{g}+F_{O G}+F_{G}\right) * \operatorname{tg} \beta$, 
where, the $\beta$ is the angle between connecting rod and cylinder center line. But it is not exact, when considering the gap $\Delta$ between the piston and cylinder liner.

As shown in Fig. 1, the piston with center mass of $O^{\prime}$, has a rock around the center of pinhole $O$, the swing angle is $\theta$, it has:

$\theta \cong \operatorname{acsin}(\Delta / l)$,

where, the $l$ is the distance of center $O$ to the piston top surface.

Given the piston is a rigid body, the impact of piston in cylinder is not a usual direct cylindrical surface shock, there is a impact contact process from point to line and surface. A simple analytical formula like Eq. (1) is not able to give the accurate description.

For the slap vibration system of piston, the multibody dynamic modal can be expressed as:

$M(q, t) \ddot{q}+\Phi_{q}^{T}(q, t) \lambda-Q(q, \dot{q}, t)=0$,

$\Phi(q, t)=0$,

where, $\Phi$ is the constraint equation of coordinate matrix $q, \Phi_{q}$ is the Jacobian matrix and $\lambda$ is the lagrange multiplier, $q, \dot{q}, \ddot{q} \in R^{n}$ are the position, velocity and acceleration vectors of the system, $t$ is the time step, $M$ is the inertia matrix of mechanical system, $Q$ is the excited load vector. All the above equations can be solved by different integral technique in ADAMS.

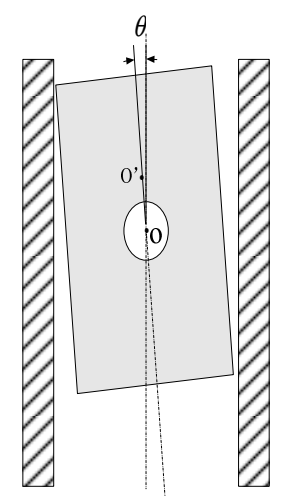

Fig. 1. The piston movement in cylinder with gap

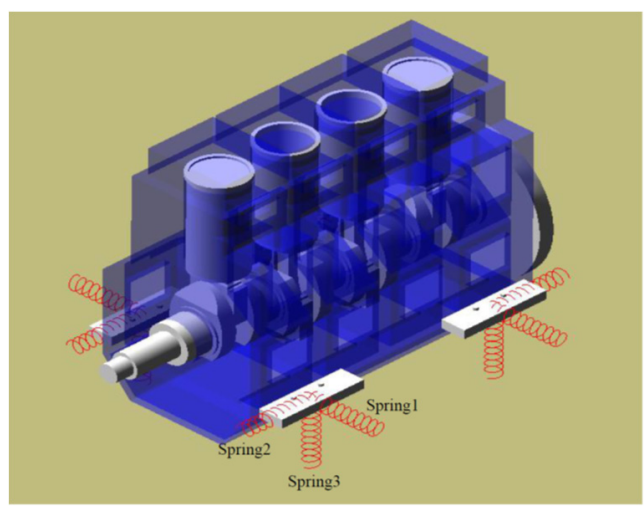

Fig. 2. The engine vibration system in ADAMS

\section{Modelling of diesel engine isolation system}

The main diesel engine parts are modeled in Pro/E, including the piston, connecting rod, engine body, crankshaft and so on. Each IGES file is imported into ADAMS. The whole body of diesel engine are built by the constraint pairs according to the working cases. In this paper, the four contact pair case of piston and cylinder are studied, which are shown in Table 1. The isolators are modeled by spring-dampers, their parameters can be settled as the constants to model the linear case, as the vertical spring $k=1 \times 10^{6} \mathrm{~N} / \mathrm{m}$ to model the elastic support, other two springs have the same parameters $k=1 \times 10^{10} \mathrm{~N} / \mathrm{m}$ to model the relative rigid support, and all the spring has the damp $c=0$. And the constant rotating speed $1000 \mathrm{rpm}$ is added to the rotating shaft.

The vibration system sketch is shown in Fig. 2, there are three spring isolators located at the four bottom supported points. The deformation and vibration phenomenon of spring 1, spring 2 and spring 3 are the analyzed. The spring 1 is taken to sense the horizontal vibration, the spring 2 to sense the longitudinal vibration and the spring 3 to sense the vertical vibration. 
Table 1. The impact analysis case

\begin{tabular}{|c|c|c|c|c|}
\hline & Case 1 & Case 2 & Case 3 & Case 4 \\
\hline Cylinder gap & 0 & $0.01 \mathrm{~mm}$ & $0.02 \mathrm{~mm}$ & $0.03 \mathrm{~mm}$ \\
\hline
\end{tabular}

\section{Analysis of system vibration}

During $0-1 \mathrm{~s}$, the vibration system is calculated with step size of $0.0004 \mathrm{~s}$. As the good convergence, the results can also be exported out to do further study.

\section{1. the engine body vibration response}

The CM (center of block mass) is changed as the increase of cylinder gap. The in-plane location curves are shown in Fig. 3, with a different range. The swing range with horizontal ellipse has a magnitude $7.26 \mathrm{~mm}, 25.62 \mathrm{~mm}, 25.57 \mathrm{~mm}$, and $25.68 \mathrm{~mm}$ for the case 1 , case 2, case 3 and case 4 , respectively. It is obviously that the swing range is enlarged with 3.5 times, and the case 3 with $0.02 \mathrm{~mm}$ gap has the relatively small value, with a decrease of $0.20 \%$ and 0.43 compared to the case 1 of $0.01 \mathrm{~mm}$ gap and case 4 of $0.03 \mathrm{~mm}$ gap. The characteristic of horizontal ellipse can be taken to identify the piston movement caused by slap.
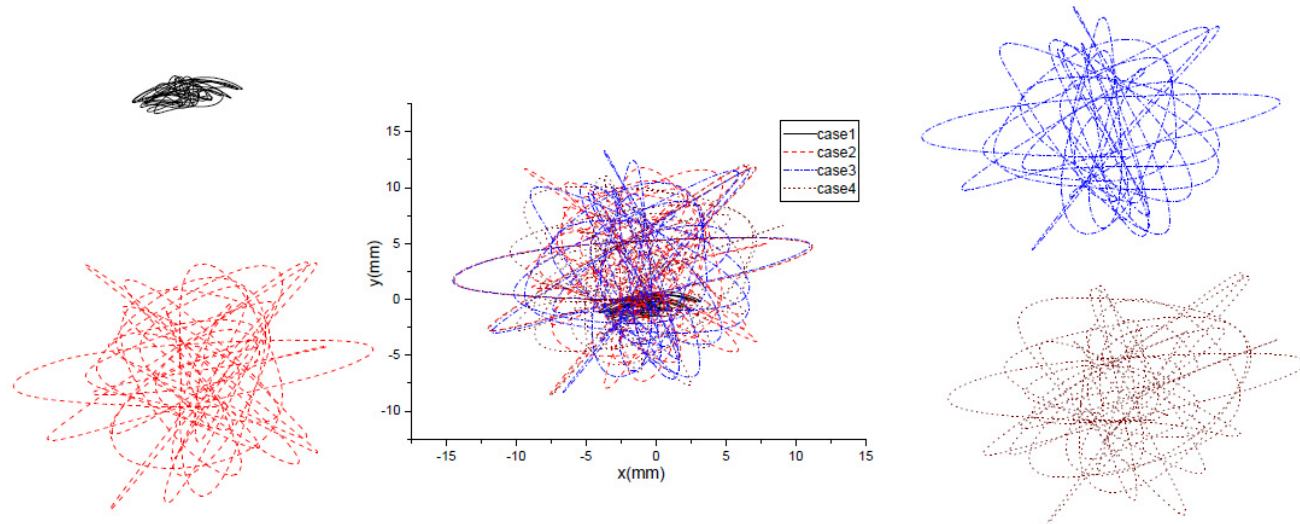

Fig. 3. The in-plane location of block CM

All the time deformation responses of three springs are shown in Fig. 4, Fig. 5 and Fig. 6. From the amplitude of such spring, it is known that the deformation of spring is amplified by the impact of piston. The deformation of spring in case 1 with no cylinder gap, is like a sinusoidal wave. As the case with cylinder gap, the deformation of spring is like harmonic wave.

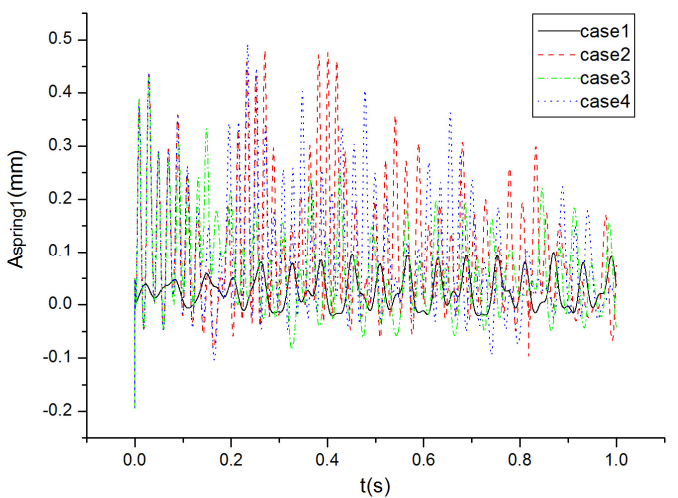

Fig. 4. The deformation of horizontal spring 1

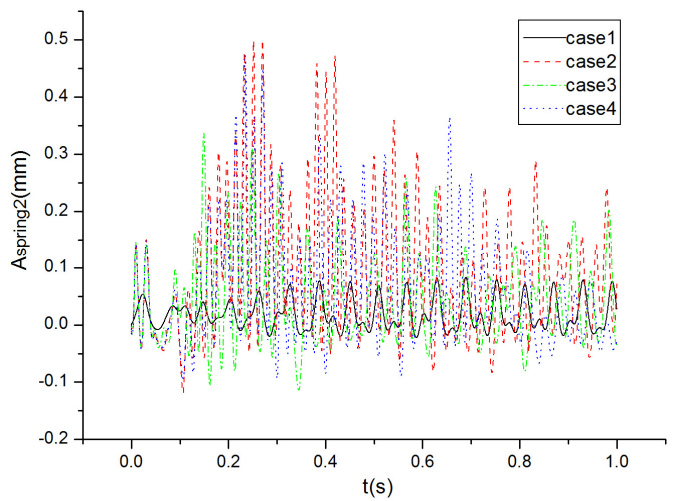

Fig. 5. The deformation of longitudinal spring 2 
After the FFT of spring deformation, the frequency spectrum of each spring are shown in Fig. 7, Fig. 8, and Fig. 9 respectively. In Fig. 7, the horizontal spring1 with no cylinder gap, has three main frequencies, as $9.77 \mathrm{~Hz}, 16.48 \mathrm{~Hz}$, and $32.96 \mathrm{~Hz}$. In Fig. 8, the longitudinal spring 2 with no cylinder gap has two main frequencies, as $16.48 \mathrm{~Hz}$ and $32.96 \mathrm{~Hz}$. In Fig. 9, the vertical spring 3 with on cylinder gap, has only one main frequency of $16.48 \mathrm{~Hz}$. As the rotating speed $1000 \mathrm{rpm}$, the fundamental excitation frequency is about $16.67 \mathrm{~Hz}$. So, the fundamental frequency can be easily sensed by the spring vibration signal.

When there is a gap between cylinder and piston, the spectrum change a lot, with a high magnitude and a series of frequency bands. As for the horizontal spring 1, when the cylinder gap is $0.01 \mathrm{~mm}$, the main frequency is a low value of $6.82 \mathrm{~Hz}$, and a high frequency band from $37.22 \mathrm{~Hz}$ to $59.55 \mathrm{~Hz}$. When the cylinder gap is $0.02 \mathrm{~mm}$, there are several main frequency bands, including $2.49 \mathrm{~Hz}, 6.20$ to $6.82 \mathrm{~Hz}, 28.68 \mathrm{~Hz}$ to $39.28 \mathrm{~Hz}$, and $49.88 \mathrm{~Hz}$. As for the case 4 with cylinder gap of $0.03 \mathrm{~mm}$, it is similar to the case 2. So, it is known that all the spectrum of horizontal spring1 have an obvious high frequency band after the cylinder with gap, with the maximum magnitude at $52.73 \mathrm{~Hz}, 34.92 \mathrm{~Hz}$, and $44.54 \mathrm{~Hz}$ for the case 2, case 3 and case 4 respectively. The frequency increase ratio is $219.96 \%, 111.89 \%$, and $168.02 \%$ respectively compared to the sensed main frequency value of $16.48 \mathrm{~Hz}$.

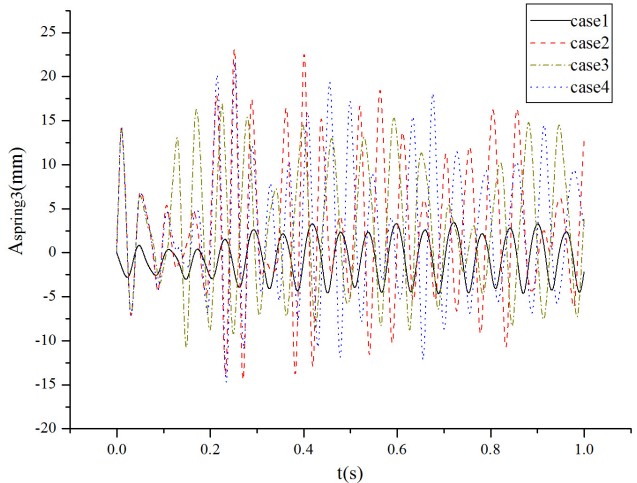

Fig. 6. The deformation of vertical spring 3

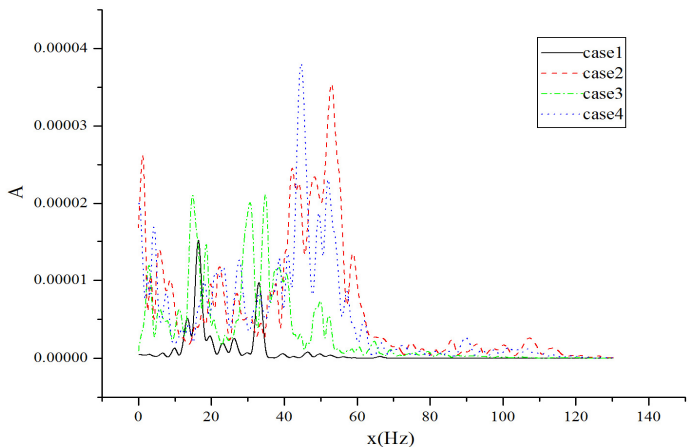

Fig. 8. The frequency spectrum of spring 2

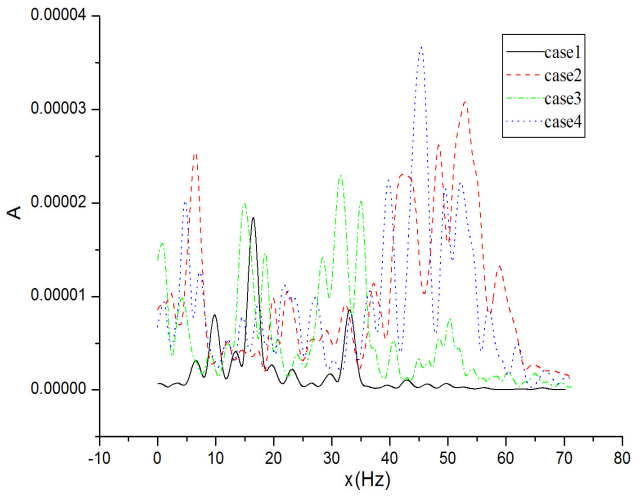

Fig. 7. The frequency spectrum of spring 1

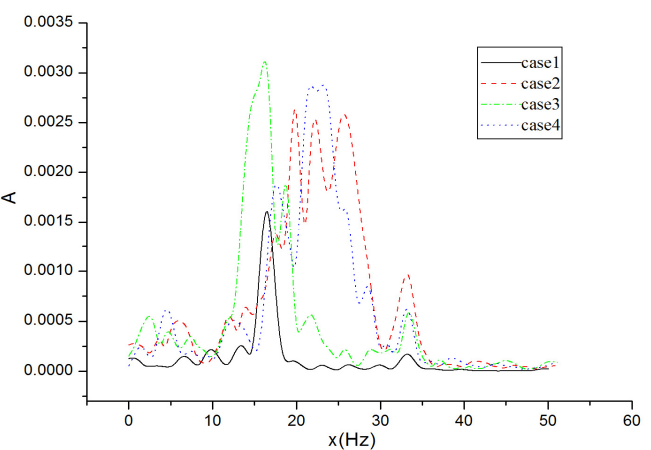

Fig. 9. The frequency spectrum of spring 3

The longitudinal spring 2 also has the like trend with spring 1 . As for the vertical spring 3 , there are no low frequency band emerging with the cylinder gap, the magnitude among the fundamental frequency $16.48 \mathrm{~Hz}$ is surged with about 2 times. The main frequency of case 2 with cylinder gap $0.01 \mathrm{~mm}$ is $19.85 \mathrm{~Hz}, 22.33 \mathrm{~Hz}$, and $25.43 \mathrm{~Hz}$. It is $16.21 \mathrm{~Hz}$, and $21.65 \mathrm{~Hz}$ to $23.51 \mathrm{~Hz}$ for the case 3 with cylinder gap of $0.02 \mathrm{~mm}$ and case 4 with cylinder gap of $0.03 \mathrm{~mm}$. 


\section{Conclusions}

This paper provides a model of diesel engine isolation system with the cylinder gap. The multi-body dynamic model with spring isolators is analyzed through ADAMS. There is an ellipse profile during each case with cylinder gap, caused by the impact between the piston and cylinder. Given the rotating condition, the position of engine body mass center has a larger circle in plane, due to the increase of cylinder gap. The bottom elastic supports of spring, have the corresponding characteristic response. That frequency spectrum characteristics can be used to easily sense the cylinder gap.

\section{Acknowledgements}

The paper is supported by the Fundamental Research Funds for the Central Universities and is also under the assistance of Fujian Province Key Laboratory of Ship and Ocean Engineering, and Fujian Engineering Research Center of Marine Detecting and Remanufacturing.

\section{References}

[1] Zhang Wenping, Li Quan, Zou Dequan Analytical study of piston secondary motion and the piston scraping force. Journal of Harbin Engineering University, Vol. 26, Issue 4, 2005, p. 493-497.

[2] Dong Hongquan, Feng Huihua, Song Yu Research on piston slap motion characteristics considering piston and cylinder liner structural deformation. Chinese Internal Combustion Engine Engineering, Vol. 37, Issue 3, 2016, p. 144-150.

[3] Chai Zhenjiang, Jiang Lv Influence rule analysis on piston-pin offset towards piston slapping forces. Chinese Journal of Construction Machinery, Vol. 11, Issue 5, 2013, p. 394-397.

[4] Xie Xiangrong, Yu Xiang, Zhu Shijian Analysis of isolation performance of vibration system on flexible foundation based on ADAMS. Journal of Vibration and Shock, Vol. 29, Issue 3, 2010, p. $185-188$.

[5] Kazuhide Ohta, Xiaoyu Wang, Atsushi Saeki Piston slap induced pressure fluctuation in the water coolant passage of an internal combustion engine. Journal of Sound and Vibration, Vol. 363, 2016, p. 329-344.

[6] Dolatabadi N., Theodossiades S., Rothberg S. J. On the identification of piston slap events in internal combustion engines using tribodynamic analysis. Mechanical Systems and Signal Processing, Vol. 58, Issue 59, 2015, p. 308-324.

[7] Fontanesi S., Giacopini M., Cicalese G., Sissa S., Fantoni S. Numerical investigation of the cavitation damage in the wet cylinder liner of a high performance motorbike engine. Engineering Failure Analysis, Vol. 44, 2014, p. 408-423.

[8] Deku Anthony, Nyanor Peter Harmonic analysis of cavitation in engine cooling fluid due to piston-cylinder assembly forces. Procedia Manufacturing, Vol. 7, 2017, p. 316-326.

[9] Dolatabadi N., Littlefair B., De La Cruz M., Theodossiades S., Rothberg S. J., Rahnejat H. A transient tribodynamic approach for the calculation of internal combustion engine piston slap noise. Journal of Sound and Vibration, Vol. 352, 2015, p. 192-209.

[10] Cho S.-H., Ahn S.-T., Kim Y.-H. A simple model to estimate the impact force induced by piston slap. Journal of Sound and Vibration, Vol. 255, Issue 2, 2002, p. 229-242.

[11] Ning Haiqiang Study of the impact of high-frequency vibration on the cavitation of engine wet cylinder liner. Ship and Ocean Engineering, Vol. 37, Issue 3, 2008, p. 59-61. 